\title{
CENTRO INTERATIVO DE CIÊNCIA E TECNOLOGIA: UMA PROPOSTA PARA O PARQUE ECOTECNOLÓGICO DE PONTA GROSSA
}

\section{INTERACTIVE CENTER FOR SCIENCE AND TECHNOLOGY: A PROPOSAL TO ECOTECHNOLOGY PARK OF PONTA GROSSA}

\author{
Andréia Antunes da Luz ${ }^{1}$; João Luiz Kovaleski ${ }^{2}$; Pedro Paulo Andrade Junior ${ }^{3 ;}$ Juliana Vitoria \\ Messias Bittencourt ${ }^{4}$; Mathias Talevi Betim ${ }^{5}$; Dayana Carla de Macedo ${ }^{6}$ \\ ${ }^{1}$ Universidade Tecnológica Federal do Paraná - UTFPR - Ponta Grossa - Brasil \\ andreia-luz@hotmail.com \\ ${ }^{2}$ Universidade Tecnológica Federal do Paraná - UTFPR - Ponta Grossa - Brasil \\ Kovaleski@utfpr.edu.br \\ ${ }^{3}$ Universidade Tecnológica Federal do Paraná - UTFPR - Ponta Grossa - Brasil \\ pedropaulo@utfpr.edu.br \\ ${ }^{4}$ Universidade Tecnológica Federal do Paraná - UTFPR - Ponta Grossa - Brasil \\ julianavitoria@utfpr.edu.br \\ ${ }^{5}$ Universidade Tecnológica Federal do Paraná - UTFPR - Ponta Grossa - Brasil \\ pgmathiasbetim@gmail.com \\ ${ }^{6}$ Universidade Tecnológica Federal do Paraná - UTFPR - Ponta Grossa - Brasil \\ dayanamacedo@yahoo.com.br
}

\begin{abstract}
Resumo
Os parques tecnológicos constituem-se como empreendimentos imobiliários, acolhendo somente empresas de base tecnológica, diferenciando-se dos parques industriais pelo ambiente de cooperação com as empresas/indústria, universidades e centros de pesquisa e a comunidade lindeira, com visão de futuro de um sistema de inovação fortalecido e contínuo, proporcionando desenvolvimento econômico e social para a comunidade onde estão inseridos. O objetivo deste artigo é propor para o projeto de implantação para do Parque Ecotenológico de Ponta Grossa um modelo de centro interativo de ciência e tecnologia. Um Centro Interativo de Ciência e Tecnologia visa por meio de suas visitas, exposições e atividades, a sustentabilidade relacionando a pesquisa científica e os avanços tecnológicos com a comunidade local. Tendo característica de um projeto dinâmico aberto ao público. Os métodos do ponto de vista da sua natureza, constitui-se uma pesquisa aplicada, com abordagem é qualitativa, constitui-se uma pesquisa bibliográfica e documental, e, basea-se na metodologia de um estudo de caso do projeto de implantação do Parque Ecotenológico. Conclui-se que um centro de ciências e tecnologia, poderia motivar e estimular os jovens a permanecerem nas escolas, despertando para o fenômeno da descoberta científica, estabelecendo a experimentação da teoria como a prática, preenchendo as inúmeras lacunas deixadas pelo ensino formal. Com a consciência já estabelecida em sua missão da importância do seu trabalho e, do seu papel essencial com esta realidade, um ambiente de sinergia das relações universidade, empresas e governos, transmitindo e transferindo o conhecimento para a comunidade.
\end{abstract}

Palavras-chave: parques tecnológicos; centro interativo de ciencia e tecnologia. 


\section{Introdução}

Um parque tecnológico também é um empreendimento que busca estimular a transferência de tecnologia para as micros e pequenas empresas, muitas vezes, englobando espaços de inovação como, por exemplo, incubadora de empresas e centros de modernização (NOCE, 2002). Parques Tecnológicos são ambientes de inovação. Como tal, instrumentos implantados em países desenvolvidos e em desenvolvimento para dinamizar economias regionais e nacionais, agregando-lhes conteúdo de conhecimento. Com isso essas economias tornam-se mais competitivas no cenário internacional e geram empregos de qualidade, bem-estar social, além de impostos (ZAMMAR; KOVALESKI; ZANETTI, 2010).

Segundo a International Association of Science Parks - IASP, um parque tecnológico é uma organização gerida por profissionais especializados, cuja idéia fundamental é incrementar a riqueza de sua comunidade, promovendo a inovação, a cooperação e a competitividade das empresas e das instituições geradoras de conhecimento instaladas no parque ou parceiras dele. Um parque tecnológico promove e gera o fluxo de conhecimento e de tecnologia entre universidades, instituições de pesquisa, empresas e mercados, promove a criação e o crescimento de empresas inovadoras mediante mecanismos de incubação e de "spin-off", e proporciona outros serviços de valor agregado, assim como espaço e instalações de alta qualidade (IASP, 2008).

Parques tecnológicos são instituições que se localizam na fronteira de dois mundos distintos, pois pretendem disponibilizar espaços que abrigam simultaneamente empresas de bases tecnológicas e inovadoras, reguladas pela lógica de mercado; e instituições de fomento, pesquisa, ciência e tecnologia que possuem políticas relacionadas à educação e produção do conhecimento científico. São experiências distintas, com culturas e hábitos diferentes que irão conviver no mesmo espaço de desenvolvimento, mas principalmente deverão estabelecer um ambiente de integração e cooperação. Vencer este paradigma de conflitos entre o acadêmico e o empresarial é o primeiro desafio para a implantação de Parques Tecnológicos (OLIVEIRA, 2008).

Sabe-se que o sucesso de um parque tecnológico é a localização, pois a identidade física do empreendimento é muito importante. Quanto mais próxima da "instituição base", geralmente uma universidade, maiores serão as vantagens decorrentes das facilidades de fomento, gerenciamento e de interação (OLIVEIRA, 2008).

Os parques tecnológicos caracterizam-se por propiciar locais de excelência para transferência de tecnologia, capacitado de infraestrutura adequada, acesso bem planejado, seus terrenos tem valores atraentes e pagamento facilitado, entre outras vantagens (VIEIRA; HAUSER, 2002). Podemos dizer que os parques tecnológicos facilitam a correlação entre a oferta e a demanda de conhecimento e inovação tecnológica, disponibilizando um ambiente de fertilização continua (ZOUAIN, 2003). 
Dessa forma, conclui-se que estas aglomerações geram possibilidades de conexões entre os parceiros, os quais podem fomentar a transformação de economias fechadas em uma rede interligada, trazendo vantagens para todos (ZAMMAR, 2010). A formação de redes e parcerias consiste em um fator-chave para o sucesso das organizações inseridas no contexto atual de elevada competitividade entre empresas (ZEN, 2005).

Os agentes responsáveis pelo desenvolvimento dos parques tecnológicos são classificados em operadores e promotores. Operadores caracterizam-se por organizações instaladas no empreendimento focando a produção de bens ou serviços tecnológicos (ZAMMAR, 2010).

Promotores se empenham para que os operadores executem suas tarefas com eficácia e eficiência, tendo como meta principal a adequação da infraestrutura, utilizando planejamento urbano e inserção de universidades e institutos de pesquisa tecnológica (VEDOVELLO, 2000). Operadores e promotores devem trabalhar juntos, unindo seus esforços para o desenvolvimento do parque tecnológico. Principais agentes no empreendimento são os empresários, as universidades e o poder público local, a união de todos estes agentes irá solidificar o resultado final deste processo (HAUSER, 1995).

A adoção de estruturas adequadas de governança pode contribuir no incremento das vantagens competitivas de uma rede bem como no alcance da sustentabilidade local, no sentido em que atua na promoção de práticas comuns entre empresas e entre os diversos atores locais, para que esses atuem de forma cooperativa na busca de resultados coletivos (SOUZA; CÂNDIDO, 2009).

Os empresários são responsáveis pela procura de tecnologia necessária para melhoria e qualificação de seus produtos e inovação (ZEN, 2005). As universidades são as geradoras de tecnologia, sua função é a realização de pesquisas para que contribuam para a melhoria da sociedade. Universidades são consideradas promotoras destes projetos em vários países, por exemplo, a Grã-Bretanha e os Estados Unidos da América. (ZAMMAR, 2010).

No Paraná existem parques tecnológicos em Curitiba, Londrina, Maringá, Cascavel, Foz do Iguaçu e Pato Branco. A região dos Campos Gerais não está contemplada com esta estrutura que deverá ser num futuro próximo um celeiro de novas empresas, onde idéias inovadoras oriundas dos cursos de doutorado, mestrado, engenharia e demais cursos da área tecnológica possam ser desenvolvidas com apoio e financiamento para pesquisas. Ponta Grossa, possuindo o maior poder de exportação, importação e PIB dos Campos Gerais, não pode perder a oportunidade para implantar o seu Parque Tecnológico (ZAMMAR, 2010).

Segundo a ANPROTEC - Associação Nacional de Entidades Promotoras de Empreendimentos Inovadores, parques tecnológicos são complexos industriais planejados de base científico-tecnológica. A missão de um parque tecnológico, além de promover espaço para negócios baseados em conhecimento, deve abrigar centros para: Pesquisa Científica; Desenvolvimento 
Tecnológico; Inovação e Incubação; Treinamento; Prospecção e Infraestrutura para Feiras, Exposições e Desenvolvimento Mercadológico.

O projeto do Parque Ecotecnológico de Ponta Grossa é uma das maiores conquistas idealizadas para o desenvolvimento da cidade de Ponta Grossa, da região dos Campos Gerais, o qual prevê aumentar a riqueza da sua comunidade, promover a cultura da inovação, a competitividade das empresas e instituições geradoras de saber, instaladas no Parque ou associadas. A partir deste contexto, o presente trabalho questiona o seguinte problema: Quais os benefícios que o Parque Ecotecnológico de Ponta Grossa proporcionará a sua comunidade lindeira?

Para responder o questionamento inicial, este artigo tem como objetivo propor para o projeto de implantação para do Parque Ecotenológico de Ponta Grossa um modelo de centro interativo de ciência e tecnologia com a comunidade, o qual estará inserido. Um centro interativo de ciencia e tecnologia para que a transferâncias de conhecimento e tecnologia sejam além das que ocorrem entre os promotores e operadores.

\section{Experiências de centros ou museus interativos de ciência e tecnologia em parque tecnológicos}

Apresenta-se abaixo as experiência de projetos de sucesso de museus e centros de ciências e tecnologia:

Relato da cidade de Viçosa, a qual possui um importante projeto piloto, que será extremamente válido no desenvolvimento de um projeto maior. Trata-se do Parque da Ciência, um projeto aberto ao público desde 1997, dentro do campus da UFV. Este Parque é hoje uma das principais atrações turísticas da cidade de Viçosa e recebe mais de 10 mil visitantes por ano. O Parque da Ciência possui diversos experimentos interativos já disponíveis para visitação, e sua apresentação pode direcionar a uma noção do que se propõe para o Museu Interativo de Ciência e Tecnologia, o local para do empreendimento foi um terreno estrategicamente escolhido no Parque, para onde voltam-se todos os olhares dos visitantes. Será, assim, um grande atrativo para visitação no local, e permitirá a interação da comunidade comum com o meio empreendedor, científico e tecnológico presentes no local, articulando as áreas empresariais, de lazer e de educação ambiental. (VIÇOSA, 2010).

Relato da iniciativa da Casa de Oswaldo Cruz, o Museu da Vida tem por objetivo informar e educar em ciência, saúde e tecnologia de forma lúdica e criativa, através de exposições permanentes, atividades interativas, multimídias, teatro, vídeo e laboratórios. É um espaço de integração entre ciência, cultura e sociedade e, por ser vinculado à Fiocruz, reflete a cultura, a missão e o compromisso social da instituição. Seus temas centrais são a vida enquanto objeto do conhecimento, saúde como qualidade de vida e a intervenção do homem sobre a vida. Situado no 
campus da Fiocruz - uma imensa área verde em meio a uma região densamente habitada na Zona Norte do Rio de Janeiro, abrigando comunidades carentes e um grande número de escolas públicas, o Museu da Vida funciona como um pólo de lazer, cultura e educação para a população dos bairros vizinhos (FIOCRUZ, 2005).

Relato do Museu de Ciências e Tecnologia da PUC-RS são os principais objetivos: disseminar conhecimentos sobre ciência e tecnologia, participar ativamente no processo de educação em todos os níveis e atuar na pesquisa científica sobre biodiversidade, paleontologia, arqueologia e conservação. Com uma grande área de exposição pública permanente, com mais de 10 mil metros quadrados (Figura 1), onde cerca de 700 equipamentos interativos estão expostos para visitação diária, o Museu apresenta exposições temáticas de nosso cotidiano, abordando questões atuais da sociedade. Possui uma equipe especializada fornece apoio pedagógico para professores de todos os níveis de ensino, a fim de que a visitação ao Museu seja um momento rico e intenso de aprendizagem. Com visitas gratuitas destinadas às escolas e outras instituições de Porto Alegre que se localizem em zonas de vulnerabilidade e risco social e tenham em seu quadro, alunos procedentes de famílias de baixa renda com impossibilidade de acessar ao Museu na condição de pagantes (MCT-PUCRS, 2011).

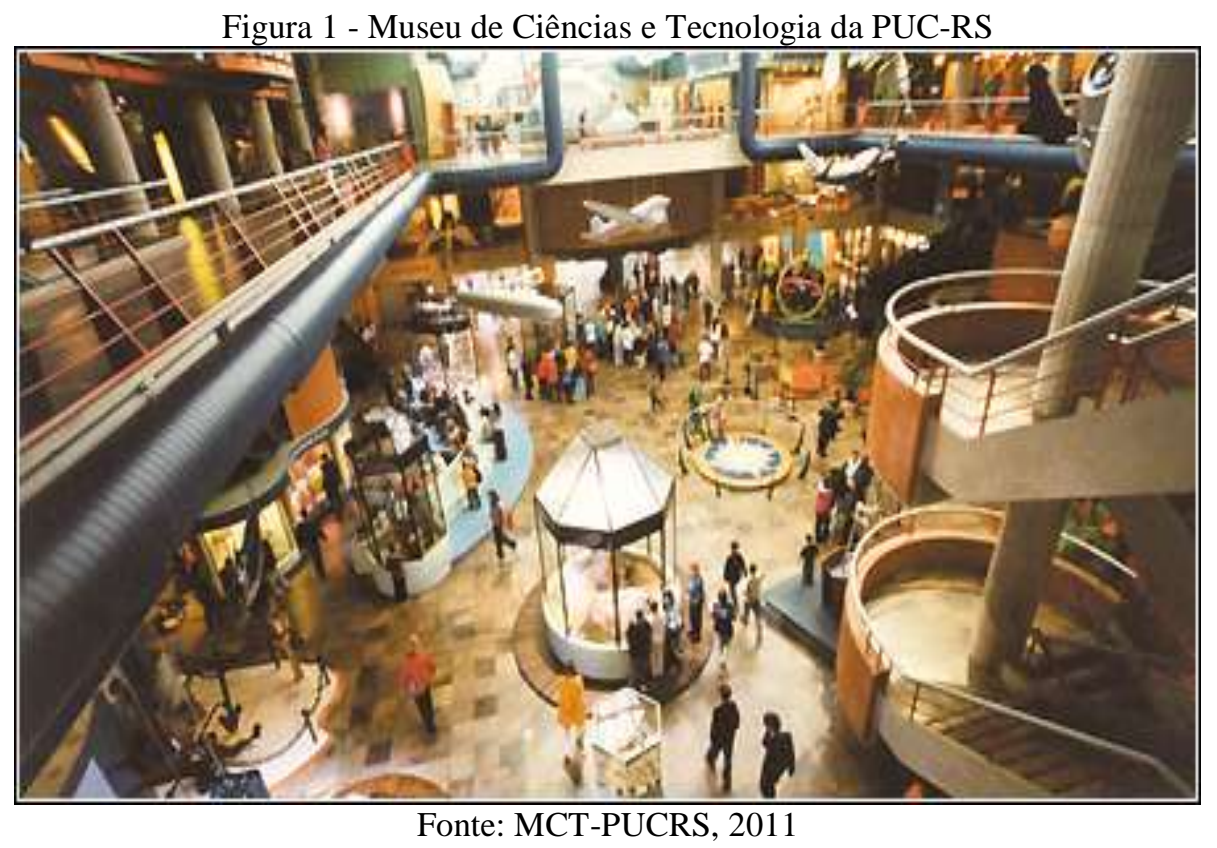

\section{Arranjo multinstituicional para a formacao do Parque Tencológico}

Ponta Grossa tem uma população de 311.697 habitantes e um Produto Interno Bruto (Valor Adicionado) - PIB de R\$ 128.644 da Agropecuária, R\$ 1.712.876 da Indústria, R\$ 2.599.169 em Serviços e Impostos sobre produtos líquidos de subsídios a preços correntes de R \$ 579.760, total do PIB a preços correntes de R \$ 5.020.449 bilhões, com um PIB per capita a preços correntes de R\$ 


\subsection{7,42 (IBGE, 2010)}

Em 1993, cerca de $66 \%$ do PIB do município era oriundo da prestação de serviços e a indústria participava com 30\%. Em 2008 percebe-se uma mudança sensível, com o setor industrial contribuindo com 34\% do PIB municipal, seguido pelo serviço com 52\%.

Contribuiu para esse perfil econômico a implantação de várias indústrias tanto no município de Ponta Grossa, pela sua localização geográfica privilegiada, quanto em outros municípios da região, como Jaguariaíva, Arapoti, Telêmaco Borba, Palmeira, entre outros. É fator decisivo para a implantação dessas indústrias a capacidade da região em fornecer mão de obra especializada e de qualidade para o setor industrial.

Na formação de mão de obra, a Universidade Estadual de Ponta Grossa - UEPG, e o Campus Ponta Grossa da Universidade Tecnológica Federal do Paraná - UTFPR, contribuíram decisivamente. A primeira, atuando na região desde 1970, e a segunda, implantada em 1993, vem suprindo a região com o aporte tecnológico necessário na formação de pessoas especializadas para o ambiente industrial e para o desenvolvimento regional.

Além disso, a cidade possui três instituições privadas de Ensino Superior, unidades do SENAI, SENAC, SEBRAE e inúmeras instituições privadas de ensino profissionalizante.

Desde 2001, a UTFPR alberga em sua estrutura uma incubadora de projetos tecnológicos, denominada Hotel Tecnológico, aonde vem fomentando a criação de empresas de base tecnológica em diversas áreas de formação. Até hoje já captou em diversos órgãos de fomento cerca de $\mathrm{R} \$ 1.000 .000,00$, revertidos na criação de empresas nas áreas de alimentos, fundição, saúde, equipamentos esportivos e softwares. Nesse mesmo ano de 2001, cerca de 10 entidades se uniram para criar a Incubadora Tecnológica de Ponta Grossa - INTECPONTA, com a mesma finalidade de fomentar a criação de empresas de base tecnológica.

Analisando toda a região dos Campos Gerais, dos quinze maiores investimentos feitos pela iniciativa privada no estado do Paraná desde 1995, sete deles estão localizados na região. Desta forma, percebe-se que o espectro industrial na região de Ponta Grossa e de toda a região é crescente, caracterizando assim um profundo interesse de industrialização da região. Com uma configuração socioeconômica da região mista, variando entre atividades agrícolas e industriais, o segmento industrial dos Campos Gerais apresenta uma estrutura bastante complexa e diversificada, preenchendo praticamente todo o espectro industrial brasileiro (PONTA GROSSA, 2010).

Assim, na verticalização de sua economia, em busca de uma inserção competitiva dentro dos novos contornos da economia mundial, surge na região a necessidade de um forte apoio tecnológico, seja na geração e difusão de novas tecnologias, na geração de oportunidades de inserção dessas tecnologias no mercado ou ainda no oportunizar a transposição de idéias em novos negócios, geradores de empregos e riqueza. 
São complexos industriais de base científico-tecnológica cuja produção se baseia em pesquisa tecnológica desenvolvida em centros de P\&D vinculados ao Parque. É um empreendimento promotor do aumento da capacidade empresarial fundamentado na transferência de conhecimento e tecnologia e fruto de um planejamento urbano entre instituições chave, a municipalidade, o governo estadual, federal, universidades e as empresas, que resulta em uma nova organização formal de propósito específico que abriga atividades de P\&D (PONTA GROSSA, 2010).

As atividades e funções do parque: $1^{\mathrm{a}}$. Etapa: 15 alqueires na localidade chamada de Chácara Thielen III (Figura 2); $2^{\mathrm{a}}$. Etapa: Trecho compreendido entre o Campus de Uvaranas da Universidade Estadual de Ponta Grossa (UEPG) e a Universidade Tecnológica Federal do Paraná (UTFPR), ladeando, em ambos os lados, o Contorno Leste (2a . Fase) (Figura 3) (PONTA GROSSA, 2010).

Figura 2 - Vista aérea da área reservado para o Parque Ecotecnológico

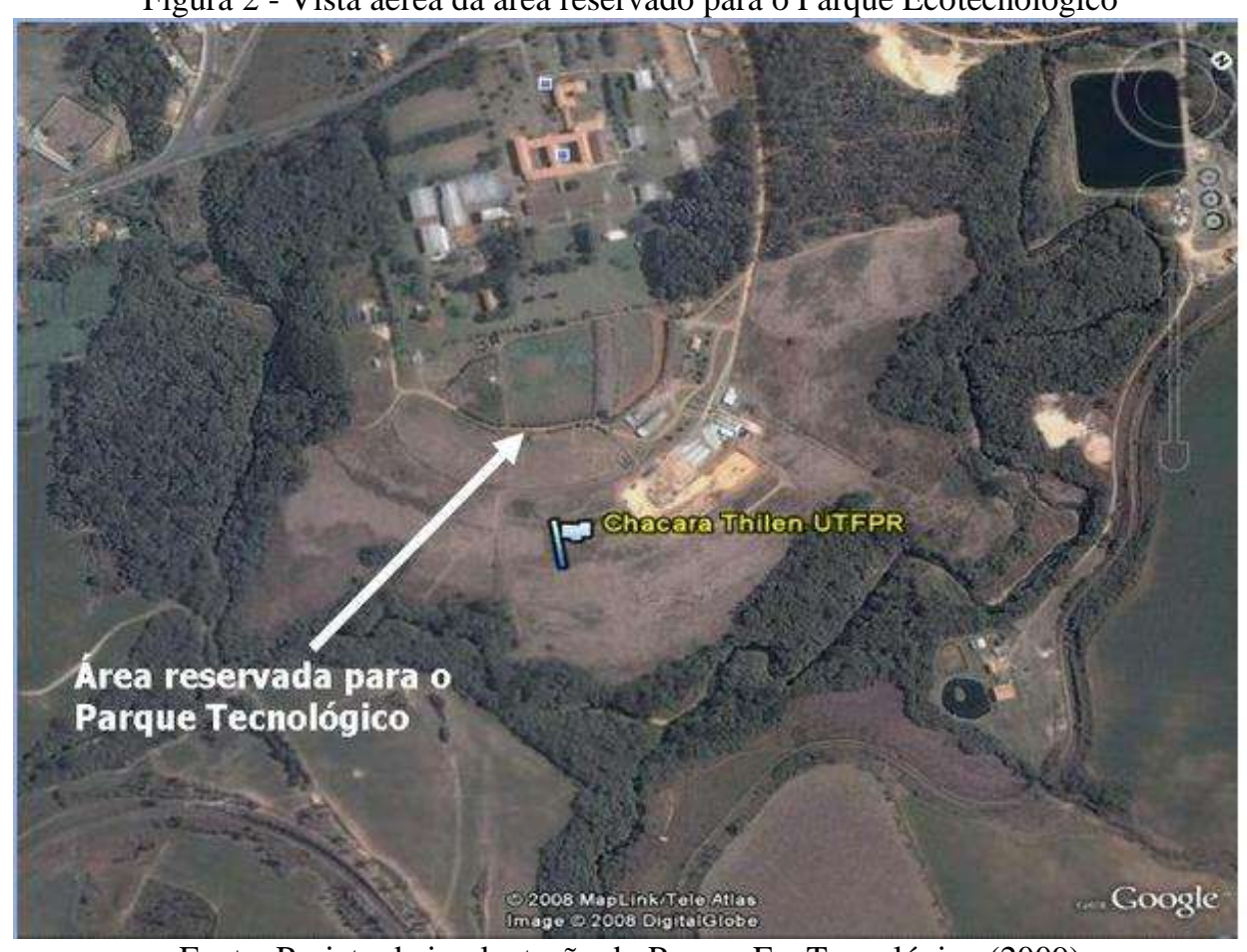

Fonte: Projeto de implantação do Parque EcoTecnológico (2009) 


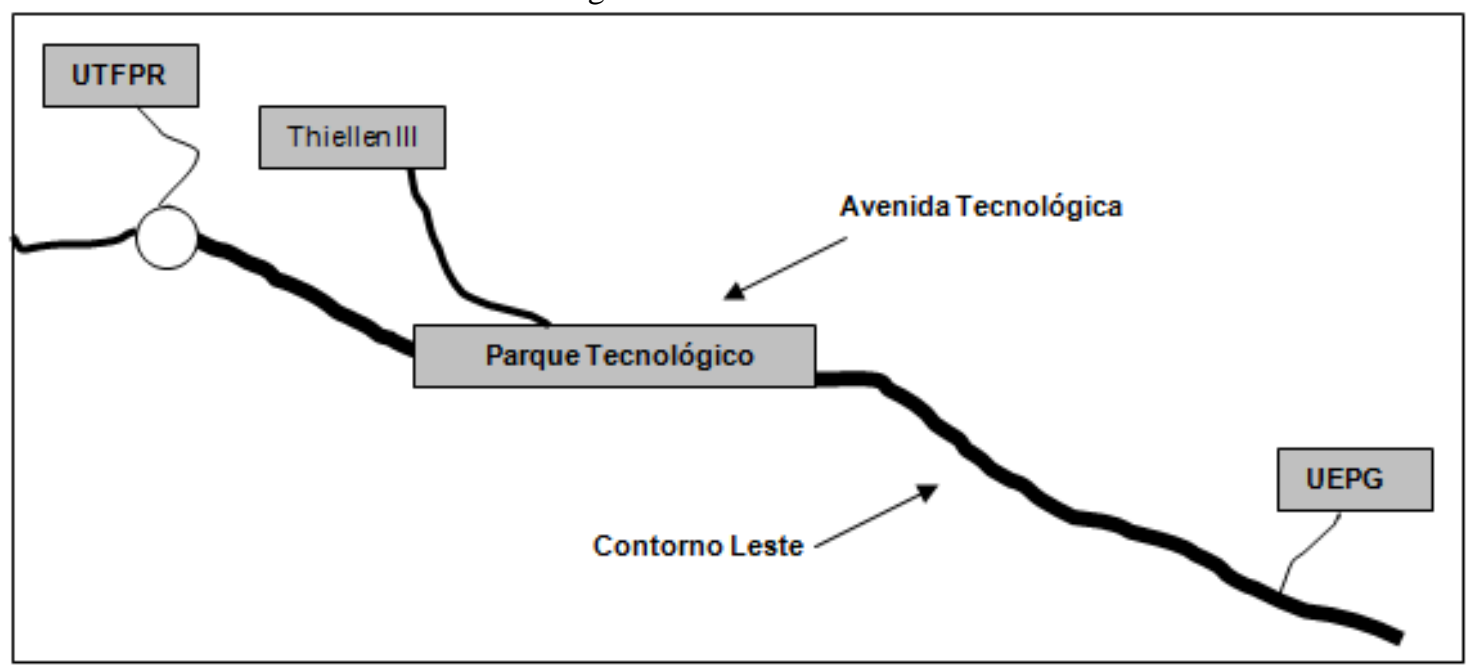

Fonte: Projeto de implantação do Parque EcoTecnológico (2009)

A partir da criação do CEFET/PR unidade de Ponta Grossa, no inicio dos anos 90, que marcou a primeira fase do Parque Tecnológico, seguindo com a fundação da incubadora tecnológica, a transformação do CEFET em UTFPR, a ligação rodoviária da UEPG e a UTFPR através da construção do contorno leste e culmina com o projeto de implantação do Parque Tecnológico de Ponta Grossa, não é coincidência que nestes atos descritos acima, onde a responsabilidade de execução foi do poder publico municipal, o atual prefeito Pedro Wosgrau Filho esteve a frente da prefeitura em 3 mandatos, em todos eles tendo uma visão inovadora e de longo prazo que projetos desta magnitude requerem (ZAMMAR; KOVALESKI; ZANETTI, 2010).

O Grupo de Trabalho desenvolveu um amplo e completo projeto para o Parque Tecnológico de Ponta Grossa, buscando no governo municipal, estadual e federal o apoio necessário para viabilizar o Parque Tecnológico de Ponta Grossa baseados nos ativos tecnológicos existentes em Ponta Grossa. O parque visa construir uma infra-estrutura com ambiente de alta qualidade urbanística que contemple a área do Parque, a Avenida Tecnológica ladeada por áreas destinadas às empresas e instituições de base tecnológica com grandes áreas verdes e de lazer com espaço para atividades esportivas e recreativas abertas à comunidade. $\mathrm{Na}$ área destinada ao Centro Administrativo do Parque deverá ser previsto a infra-estrutura para a Administração, a Incubadora Tecnológica, os Hotéis Tecnológicos, Laboratórios, Centro de Convenções com auditório para 1.000 lugares, Centro de Feiras e Centro de Negócios entre outros. Devendo ser previsto também espaço para uma futura estrutura hoteleira.

Ponta Grossa tem uma vocação muito forte nas áreas de Tecnologia da Informação e Comunicação (TIC), Metalmecânica, Materiais, Eletro-eletrônica, Agro-alimentos e Madeira, suficientes para garantir a viabilidade do projeto do Parque e ainda contando outros setores emergentes como a biotecnologia e a nanotecnologia. 
Outro ponto alto do Parque será atrair indústrias baseadas em pesquisa ou atividades de pesquisa e desenvolvimento que queiram se beneficiar da massa crítica existente no pólo universitário de Ponta Grossa. Apresentando-se como um grande atrativo para empresas de base tecnológica e visitação no local, e permitindo a interação da comunidade com o meio científico e tecnológico que o empreendedor está inserido, através da articulação de atividades de lazer e educação ambiental.

O estado do projeto de criação do parque tecnológico de Ponta Grossa em maio de 2010 é o seguinte:

- Projeto de lei No 90/2010 que cria o Parque Tecnológico de Ponta Grossa foi aprovado em primeira votação no dia 24/05/2010, e em segunda votação no dia 26/05/2010, com aprovação de 100\% dos vereadores da Câmara Municipal de Ponta Grossa, e agora partindo para a sanção do prefeito municipal;

- Lei No 10.269, de 31/05/2010 cria o Parque Tecnológico de Ponta Grossa com uma área de $726.000 \mathrm{~m} 2$, onde a UTFPR/PG está instalada dentro do parque e, via contorno leste, que será concluído em 2010, a UEPG está a 3,5 km do parque (PONTA GROSSA, 2010).

Além do pioneirismo do projeto para a cidade de Ponta Grossa, o que é inovador é a proposta de um modelo de um centro interativo de ciencia, tecnologia e inovação junto ao parque EcoTecnológico, o qual, visa por meio de suas visitas, exposições e atividades, na inovação tecnológica relacionando a pesquisa científica e os avanços tecnológicos com a comunidade local e seus acontecimentos com o desenvolvimento do local em que está inserido. Por tratar-se de uma obra de grande extensão, verificam-se as inevitáveis interferências nas comunidades lindeira.

\section{Necessidade da troca de tecnologia do parque com os lindeiros}

Ensinar é tarefa da escola. Este é um consenso em todo o mundo, que chamamos civilizado. À família, à sociedade, cabe educar: transmitir a língua materna, hábitos e costumes, valores morais e cívicos. Até há algum tempo atrás era possível supor que, dessa forma, todo conhecimento humano seria alcançado e transmitido de geração a geração. Hoje, entretanto, isso não é mais verdade. Mesmo que a escola fosse, por hipótese, uma instituição eficiente, fiel a seus objetivos, livre das críticas e queixas que atualmente se voltam contra ela até nos países desenvolvidos, serlhe-ia impossível abarcar todo esse conhecimento. Não há tempo, não há espaço em seus limitados currículos e programas e, mais ainda, não há como acompanhar o vertiginoso progresso científico e tecnológico dos nossos dias (GAPAR, 1993).

Dessa forma a distância entre o saber abrangido pela escola e aquele gerado e acumulado pelo homem cresce assustadoramente. Cada vez mais a humanidade, em sua imensa maioria, está 
alheia às suas próprias conquistas. A insatisfação, a inconformidade com esta realidade tem levado muitos, indivíduos, instituições, empresas e governos, a procurar formas alternativas de acompanhar e transmitir todo este acervo científicocultural. A educação formal, escolar, tem sido complementada ou acrescida de uma educação não-formal e informal, extra-escolar, que tem de certa forma oferecido à sociedade o que a escola não pode oferecer (GAPAR, 1993).

A limitação da escola também reside em suas instalações, equipamentos e laboratórios, sempre restritos e orientados à suas aplicações pedagógicas. Mesmo que existam, sejam adequados e atualizados, dificilmente permitirão ou oferecerão espaço para atividades puramente qualitativas, informativas ou mesmo voltadas apenas para o encantamento e a emoção (GAPAR, 1993).

O alcance dos museus e centros de ciências não pode ser comparado aos meios de comunicação de massa, embora em alguns países desenvolvidos ele já seja considerável, mas o impacto de sua atuação e a credibilidade de suas propostas pode compensar essa aparente desvantagem (GAPAR, 1993).

Proporcionar condições de interação é justificar uma forma convincente da necessidade da existência de um centro interativo de ciência, tecnologia e inovação. Além disso, é importante salientar a demanda da população em relação à ciência e tecnologia.

Em relação ao ensino a cidade de Ponta Grossa, apresenta os seguintes resultados sobre o ano de 2009, segundo IBGE, 2010. O total das matrículas no ensino fundamental foi de 53.686, destas 42\%, ou seja, 22.197 para escola pública estadual, 43\% ou 23.206 para a escola pública municipal e $15 \%$ ou 8.283 na escola privada. E total das matrículas para o ensino médio é de 13.862, destas, $80 \%$ ou 11.069 na escola pública estadual, $2 \%$ ou 291 na escola pública federal e apenas $18 \%$ ou 2.502 na escola privada.

Percebe-se que os números de matrículas no ensino médio é $387 \%$ menor que as matrículas efetuadas no ensino fundamental. Também que $85 \%$ no ensino fundamental e $80 \%$ ensino médio vem da rede estadual e municipal. Estas pesquisas apresentam indicações a respeito das matrículas realizadas, evidencia a necessidade de melhorias no ensino público. Comprovando a necessidade de investimentos que propiciem o despertar para a formação de inovadores, pois parte dos alunos de ensino médios irão ingressar no ensino de terceiro grau e posteriormente poderão participar de projetos inovadores.

Não menos importante é estabelecer uma infraestrutura para a implantação e a consolidação de um centro de ciência e tecnologia visando à implementação de serviços que deverão apresentar relevância de ciência e tecnológica, entre o ensino e as atividades industriais.

Assim o parque tecnológico não somente propiciará o desenvolvimento atual como também o de futuras gerações nestes empreendimentos cumprindo assim os preâmbulos da sustentabilidade deste parque nas gerações futuras. 
A eficiência do centro interativo, principalmente em relação à aprendizagem, pode oferecer condições para despertar o interesse sobre a aprendizagem. Pode-se afirmar que há um amplo campo de desenvolvimento a ser explorado pelo centro interativo com a comunidade.

\section{Métodos}

Do ponto de vista da sua natureza, constitui-se uma pesquisa basica, em relação aos seus objetivos apresenta-se como descritiva e a forma de abordagem é qualitativa. Do ponto de vista dos procedimentos técnicos constitui-se uma pesquisa bibliográfica, através de material já publicado, constituído tese, artigos de periódicos e material disponibilizado na Internet e uma pesquisa documental foi realizado uma análise de conteúdo em documentos, para a geração de informações a partir de dados oficiais da realidade da população selecionada, facilitando a análise dos dados que foram levantados. A pesquisa é baseado na metodologia de um estudo de caso do projeto de implantação do Parque Ecotenológico. Em relação a população, a pesquisa foi realizada na cidade de Ponta Grossa - Paraná, mais especificamente no projeto de implantação do Parque Ecotenológico.

\section{Proposta de um centro interativo de ciencia e tecnologia para o Parque Ecotenológico de Ponta Grossa e consideracoes finais}

A criação do Parque Tecnológico dos Campos Gerais, congregando as potencialidades da região, reunindo os ativos tecnológicos dos Campos Gerais do ambiente acadêmico, industrial e do poder público, estabelecerá uma situação favorável para que se possa dar continuidade ao desenvolvimento que a região vem presenciando desde a década passada. Desta forma, percebe-se que o espectro industrial na região de Ponta Grossa e de toda a região é crescente, caracterizando assim um profundo interesse de industrialização da região. Com uma configuração socioeconômica da região mista, variando entre atividades agrícolas e industriais, o segmento industrial dos Campos Gerais apresenta uma estrutura bastante complexa e diversificada, preenchendo praticamente todo o espectro industrial brasileiro.

Propiciar a comunidade local o contato com outras realidades do ensino científico e cultural. Para possibilitar experiências didáticas inovadoras, em educação formal e não-formal, para estudantes e professores de escolas e colégios da região.

As visitas e apresentações deverão ser agendadas com a equipe e os membros do Núcleo centro interativo de ciencia, tecnologia e inovação para o Parque EcoTenológico. Na proposta básica as atividades do centro interativo em relação a visitas, estabelecer uma forma de prever o mais precisamente a possível aprendizagem do visitante. De acordo com Falk (1983) em pesquisas realizadas em museus e centros de ciência, essa aprendizagem pode ser vista a partir de três 
perspectivas: (I) a do objeto ou experimento exposto, segundo a qual o fator determinante do comportamento e conseqüente aprendizagem do visitante é o que está exposto, a sua apresentação, iluminação, textos informativos, etc; (II) a do visitante, pela qual o fator mais relevante é sua experiência e conhecimento anterior, e (III) a da locação (setting), segundo a qual o comportamento e conseqüente aprendizagem do visitante é determinado, basicamente, por fatores sócio-ambientais e independe da qualidade dos objetos expostos ou de sua bagagem cultural (algo como o comportamento de uma pessoa num teatro ou cinema, que não depende do espetáculo nem da bagagem cultural de cada um).

A proposta pretende desenvolver um amplo espectro de atividades a serem desenvolvidas:

- apresentações de pesquisas realizadas pelas empresas incubados no parque;

- apresentações de pesquisas e projetos de extensão realizados por professores, pesquisadores e alunos à comunidade, industrias e imprensa;

- criação de showroom de protótipos de projetos desenvolvidos nas empresas do parque e incubadas;

- infra-estrutura de apoio (laboratórios, equipamentos, materiais, textos, etc) a professores e alunos para realização de projetos e pesquisas;

- promoção de eventos, exposições e feiras de ciência, tecnologia e inovação;

- promoção de cursos introdutórios nas áreas de Tecnologia da Informação e Comunicação (TIC), Metalmecânica, Materiais, Eletro-eletrônica, Agro-alimento e Madeira, e setores emergentes como a biotecnologia e a nanotecnologia;

- consulta e empréstimo de livros, revistas, etc;

- exibição de filmes.

A necessidade da ação direta e indireta em parcerias com as universidades e os meios de comunicação, por meio estes podem encontrar o material necessário para desenvolver sua função e, reciprocamente, divulgar essas atividades.

Conclui-se que um centro de ciências e tecnologia, poderia motivar e estimular os jovens a permanecerem nas escolas, despertando para o fenômeno da descoberta científica, estabelecendo a experimentação da teoria como a prática, preenchendo as inúmeras lacunas deixadas pelo ensino formal. Devido às limitações dos currículos e programas de ensino, os quais, não conseguem acompanhar o progresso científico e tecnológico na mesma velocidade. Neste contexto, um centro de ciências, tecnologia e inovação complementaria e reduziria essa distância. Com a consciência já estabelecida em sua missão da importância do seu trabalho e, do seu papel essencial com esta realidade, um ambiente de sinergia das relações universidade, empresas e governos, transmitindo e transferindo o conhecimento para a comunidade. 


\begin{abstract}
The technology parks are ventures estate, accepting only technology-based firms, differentiating itself from the industrial parks by ambience of cooperation with business / industry, universities and research centers and the bordering communities, with future vision of a system of innovation strong and continuo, providing economic and social development for their community where they fit. The aim of this paper is to propose for the deployment project for the Park Ecotenológico Ponta Grossa a model interactive of center science and technology with the community. An Interactive Center for Science and Technology aims through their visits, exhibitions and activities, the sustainability related the research scientific and advance technological with the local community. Having characteristic of a dynamic project open to public. The methods in terms of its nature, it constitutes an applied research with a qualitative approach, it constitutes a bibliographic and documentary research, and, builds on the methodology of an es $\neg$ everything in case of deployment project Ecotenológico Park. Concluded that a center of science and technology, could motivate and encourage young to remain in schools, awakening to the phenomenon of scientific discovery, establishing the experimentation of the theory with practice, filling the gaps left by the formal education. With the consciousness already established in its mission of the importance of the its work and, their essential role with this reality, an environment of synergy of the relationships university, business and governments, transmitting and transferring the knowledge to the community.
\end{abstract}

Key-words: technological park; interactive center of science and technology.

\title{
Referências
}

FALK, J. H. - Time and behavior as predictors of learning. Science Education. 67/2, 1983, pg. 267 a 276.

Fundação Oswaldo Cruz - Fiocruz. Destaques. 2005. Disponível em:

<http://www.fiocruz.br/cgi/cgilua.exe/sys/start.htm?infoid=26\&sid=17\&tpl=printerview>. Acesso em: 16 fev. 2011.

GASPAR, A. Museus e centros de ciências - conceituação e proposta de um referencial teórico. 1993. 118 f. Tese

(Doutorado em Didática). Universidade de São Paulo - Faculdade De Educação. 1993. Disponível em:

<http://www.casadaciencia.ufrj.br/Publicacoes/Dissertacoes/gaspar-tese.pdf>. Acesso em: 10 dez. 2010.

HAUSER, G. Parques tecnológicos europeus e espaço urbano. In: PALADINO, Gina (org.), MEDEIROS, Lucília A.. (org.). Parques Tecnológicos e Meio Urbano: artigos e debates. Brasília: Anprotec, GTU International, 1997. p. 8599.

IASP - International Association of Science Parks. Disponível em: <http://www.iaspworld.org>. Acesso em: 10 out. 2010.

IBGE - Instituto Brasileiro de Geografia e Estatística. Cidades, 2010. Disponível em:

<http://www.ibge.gov.br/cidadesat/topwindow.htm? >. Acesso em: 10 out. 2010.

NOCE, A. F. R. O processo de implantação e operacionalização de um parque tecnológico. UFSC, 2002.

PONTA GROSSA, 2010. Projeto de implantação do Parque EcoTecnológico de Ponta Grossa.

Pontifícia Universidade Católica do Rio Grande do Sul - PUCRS. Museu de Ciências e Tecnologia- MCT. Disponível em: < http://www.pucrs.br/mct/>. Acesso em: 16 fev. 2011.

OLIVEIRA, F. H. P. O desafio de implantar parques tecnológicos. Instituto Inovação, Belo Horizonte, 2008.

VEDOVELLO, C. Aspectos relevantes de parques tecnológicos e incubadoras de empresas. Revista do BNDES, v. 7, p.273-300, 2000.

VIÇOSA, 2010. Parque Tecnológico. Disponível em:

$<$ http://www.centev.ufv.br/parque/interna.php?area=programa\&idIdioma=1\&sis=3\&escolha=2>. Acesso em: 20 out. 2010.

VIEIRA, C. R. B.; HAUSER, G. Porto Alegre - a construção de um habitat de inovação. In: XII Seminário Nacional de Parques Tecnológicos e Incubadoras de Empresas, 2002, São Paulo, SP. Anais... São Paulo: 2002.

ZAMMAR, G. Infraestrutura para Implantação de Empresas de Base Tecnológica - Parque Tecnológico de Ponta Grossa. 2010. 105 f. Dissertação (Mestrado em Engenharia da Produção). Programa de Pós-Graduação em Engenharia 
de Produção, Universidade Tecnológica Federal do Paraná - Campus Ponta Grossa. 2010. Disponível em: < http://www.pg.utfpr.edu.br/dirppg/ppgep/dissertacoes/arquivos/146/Dissertacao.pdf>. Acesso em: 20 out. 2010.

ZAMMAR, G.; KOVALESKI, J. L.; ZANETTI, S. G. Parque Tecnológico de Ponta Grossa: um ambiente que necessita de qualidade na gestão. Revista Gestão Industrial. v. 06, n. 02: p. 196-212, 2010. Disponível em: <http://www.pg.utfpr.edu.br/depog/periodicos/index.php/revistagi/article/view/613/484>. Acesso em: 16 fev. 2011.

ZEN, A. C. A articulação e o desenvolvimento dos parques tecnológicos: O caso do Programa Porto Alegre Tecnópole - Brasil. Altec 2005.

ZOUAIN, D. Parques Tecnológicos propondo um modelo conceitual para Regiões Urbana - O Parque Tecnológico de São Paulo. Tese de Doutorado. São Paulo: USP, 2003.

\section{Dados dos autores:}

\section{Nome completo: Andréia Antunes da Luz}

Filiação institucional: Universidade Tecnologica Federal do Parana - UTFPR-PG

Departamento: Programa de Pos-graduação em Engenharia de Produção - PPGE da Universidade Tecnologica Federal do Parana - UTFPR-PG

Função ou cargo ocupado: Mestranda

Endereço completo para correspondência (bairro, cidade, estado, país e CEP): Av Monteiro Lobato, s/n - Km 04, Ponta Grossa, Paraná, Brasil - CEP: 84016-210

Telefones para contato: (42) 3236-5322 8814-3167

e-mail:andreia-luz@hotmail.com

\section{Nome completo: João Luiz Kovaleski}

Filiação institucional: Universidade Tecnologica Federal do Parana - UTFPR-PG

Departamento: Programa de Pos-graduação em Engenharia de Produção - PPGE da Universidade Tecnologica Federal do Parana - UTFPR-PG

Função ou cargo ocupado: Coordenador e Professor

Endereço completo para correspondência (bairro, cidade, estado, país e CEP): Av Monteiro Lobato, s/n - Km 04, Ponta Grossa, Paraná, Brasil - CEP: 84016-210

Telefones para contato: (42) 3220-4800

e-mail:kovaleski@utfpr.edu.br

\section{Nome completo: Pedro Paulo de Andrade Junior}

Filiação institucional: Universidade Tecnologica Federal do Parana - UTFPR-PG

Departamento: Programa de Pos-graduação em Engenharia de Produção - PPGE da Universidade Tecnologica Federal do Parana - UTFPR-PG

Função ou cargo ocupado: Professor

Endereço completo para correspondência (bairro, cidade, estado, país e CEP): Av Monteiro Lobato, 
s/n - Km 04, Ponta Grossa, Paraná, Brasil - CEP: 84016-210

Telefones para contato: (42) 3220-4800

e-mail:pedropaulo@utfpr.edu.br

Nome completo: Juliana Vitoria Messias Bittencourt

Filiação institucional: Universidade Tecnologica Federal do Parana - UTFPR-PG

Departamento: Programa de Pos-graduação em Engenharia de Produção - PPGE da Universidade Tecnologica Federal do Parana - UTFPR-PG

Função ou cargo ocupado: Professora

Endereço completo para correspondência (bairro, cidade, estado, país e CEP): Av Monteiro Lobato, s/n - Km 04, Ponta Grossa, Paraná, Brasil - CEP: 84016-210

Telefones para contato: (42) 3220-4800

e-mail: julianavitoria@utfpr.edu.br

Nome completo: Mathias Talevi Betim

Filiação institucional: Universidade Tecnologica Federal do Parana - UTFPR-PG

Departamento: Programa de Pos-graduação em Engenharia de Produção - PPGE da Universidade Tecnologica Federal do Parana - UTFPR-PG

Função ou cargo ocupado: Mestrando

Endereço completo para correspondência (bairro, cidade, estado, país e CEP): Av Monteiro Lobato, s/n - Km 04, Ponta Grossa, Paraná, Brasil - CEP: 84016-210

Telefones para contato: (42) 3220-4800

e-mail: pgmathiasbetim@gmail.com

Nome completo: Dayana Carla de Macedo

Filiação institucional: Universidade Tecnologica Federal do Parana - UTFPR-PG

Departamento: Programa de Pos-graduação em Engenharia de Produção - PPGE da Universidade Tecnologica Federal do Parana - UTFPR-PG

Função ou cargo ocupado: Mestrando

Endereço completo para correspondência (bairro, cidade, estado, país e CEP): Av Monteiro Lobato, s/n - Km 04, Ponta Grossa, Paraná, Brasil - CEP: 84016-210

Telefones para contato: (42) 3220-4800

e-mail: dayanamacedo@yahoo.com.br

Enviado em: 15/03/2011

Aprovado em: 30/09/2011 